The Egyptian Journal of Hospital Medicine (January 2021) Vol. 82 (3), Page 399-403

\title{
Post Chemotherapy Balance Exercises in Children with Acute Lymphoblastic Leukemia
}

Radwa Mohamed Mohamed Zakaria*1, Mohamed Maher Elkeblawy², Abdelmoneim Ahmed

Abdelmoneim $^{3}$, Hussein Gamal Hussein Mogahed ${ }^{4}$

${ }^{1}$ Physical Therapist at Benha Fever Hospital, ${ }^{2}$ National Center of Research, ${ }^{3}$ Department of Internal Medicine and Hematology, Faculty of Medicine, Benha University, ${ }^{4}$ Department of

Physical Therapy for Surgery, Faculty of Physical Therapy, Cairo University, Egypt

*Corresponding author: Radwa Mohamed Mohamed Zakaria, Mobile: (+20) 01206711197,

E-Mail: radwa.Zakaria87@gmail.com

\section{ABSTRACT}

Background: Acute lymphoblastic leukemia (ALL) is the most common type of childhood cancer; Children with this type of leukemia have poor postural balance, which is one of the side effects of chemotherapy. Objective: To evaluate the therapeutic effect of static and dynamic balance exercises using both sides up (BOSU) ball on balance in children with acute lymphoblastic leukemia after completing their 6 months-chemotherapy treatment.

Patients and methods: Thirty children patients of both sexes (18 boys and 12 girls) were participated in this study, who were selected from Benha Children Hospital with acute lymphoblastic leukaemia and had chemotherapy treatment for 6 months participated in this study. They were randomly assigned to 2 groups of an equal number, control group, 15 child patients who were $5-8$ years of age $(6.53 \pm 1.13)$ that underwent gait training therapy and study groups, 15 child patients who were $5-8$ years of age $(6.67 \pm 1.11)$, that underwent the same program in addition to static and dynamic balance training program by using BOSU ball. Results: There was a significant improvement of balance performance in study group more than control group. Conclusion: Balance exercises using BOSU ball can be used effectively in treating balance defect post chemotherapy in children with acute lymphoblastic leukemia. Keywords: Acute lymphoblastic leukemia; Balance exercises; Post chemotherapy side effect.

\section{INTRODUCTION}

Acute lymphocytic leukemia (ALL) is the most common type of childhood cancer, and its incidence is steadily increasing. The 5-year survival rate has also risen up to more than $85 \%$ in high income countries, but treatment has adverse impacts. Because of this improvement in survival rate, attention has shifted toward understanding the adverse impacts of cancer treatment such as chemotherapy-induced neuropathy and loss of bone mineral density. Poor balance is an adverse effect that is less investigated for cancer treatment ${ }^{(\mathbf{1})}$.

Balance defects seen in children and adolescents having been through neurotoxic treatment for cancer, despite balance impairments occurring during cancer treatment improve over time, their mean scores remain below population norms at 6 months post treatment for many forms of cancer ${ }^{(2)}$.

Motor skills in children grow fast and any intermission of this development, e.g. during the course of a cancer disease and its treatment, leads to a lateness in a number of these motor skills ${ }^{(3)}$. This can be accompanied by psychosocial effects in affected individuals when dealing with other members of their same age group. A decrease of balance ability is supposed to be one side effect of childhood cancer, according to the cancer type, the treatment, and the time elapsed since treatment ${ }^{(4)}$.
The advantages of physical exercise training interventions that act on many disabilities in children such as the skeletal system, skeletal muscle, neuromuscular system, heart and lung, cardiovascular system, fatigue, disturbances of postural balance, and metabolic changes were examined. These side effects can be prevented or significantly reduced by introducing a physical exercise program during or shortly after cancer treatment. Several interventions are introduced to reduce the level of vulnerability caused by disease and thus suggest the importance of physical training activity in improving children's quality of life ${ }^{(5)}$. Balance training is an effective intervention to improve static postural sway and dynamic balance. Both sides up (BOSU) ball is a tool that helps enhance postural balance and adds extra intensity to many different types of training; upper and lower body, core and cardio, challenging body balance, improving core strength, stability, moreover it adds fun to children ${ }^{(6)}$.

Also, gait training can help in improve postural balance as it helps in strengthening the muscles of the body, improves balance and posture, builds up endurance, develops muscle memory, retrains the legs for repetitive movement, and reduces the risk of falls, while increasing body movements ${ }^{(7)}$. 


\section{MATERIALS AND METHODS}

Thirty children patients of both sexes (18 boys and 12 girls) ranging in age from 5 to 8 years, participated in this study. They were selected from Benha Children Hospital. They were enrolled in this study if they were diagnosed with acute lymphoblastic leukaemia (ALL) and had their chemotherapy treatment for 6 months. They could stand independently, All children were able to follow instructions during testing and treatment procedures. Children were excluded if they had any other type of leukemia, had high risk ALL (received more intensified chemotherapy dose), had neurological disorders that could affect balance, diagnosed with another condition that could affect balance (i.e., fractures, symptomatic osteonecrosis), with visual perceptual disorders, sensory or hearing deficits or had psychological disturbances.

\section{Ethical approval:}

Subjects in this study were informed about the study procedure and signed a written informed consent. Approval of the Ethical Committee of Cairo University was obtained.

The included subjects were randomly divided to two groups of equal number, control group, which received gait training therapy and study groups, which received the same program in addition to balance training program (static and dynamic) in BOSU ball. The treatment was set for 90 min. for 3 sessions/week for 3 successive months.

Instrumentation: Instrumentation used for evaluation was pediatric balance scale (PBS). Recording balance score was at these times: T1: one week before $1^{\text {st }}$ chemotherapy dose (base line), T2: just after completing six successive months of chemotherapy treatment (pre-treatment), T3: three successive months later after children received physiotherapy treatment (post-treatment).

\section{Pediatric balance scale:}

The pediatric balance scale (PBS), modulation of Berg's Balance Scale, was developed as a balance scale for school age children with mild to moderate motor defects. It is 14-items scale which is easy to conduct, doesn't require special tools, and can be finished in $<20 \mathrm{~min}$. A 0 to 4 grading scale provides a quantitative and qualitative measure of performance. A total numeric score is obtained at the end of the test ${ }^{(8)}$.

\section{Evaluation procedure: \\ (Repeated measure design)}

Before starting the test, the therapist is responsible for explaining each item to the children, at first, every item was requested from the child and then only one opportunity was given to practice the item before the real performance. Each item was scored on a scale of 0 to 4 . During practice, the therapist provided physical assistance and/or visual or auditory cues, if needed, to make sure that the child fully understood what he/she was supposed to be doing. On average, it takes 15 minutes for each child to finish the test completely. The test environment setting was a quiet room, and away from physical obstacles. The evaluation area was fixed during the number of assessments. The second session of the test was held 3 months after the first session. Attendance of family members was optional while performing the test ${ }^{(9)}$.

\section{Treatment Instrumentation: Both Sides Up Ball (BOSU):}

BOSU ball is a modern means that helps in acquiring the basic physical fitness elements, which in turn have a better effect on performing the basic skills in various activities. It is a strong rubber hemisphere fixed to a solid circular base of non-slip synthetic fibers, and the ball is limited by prominent lines on its full rotation not slip from above or from the side and can be used and work on it from all directions. The BOSU ball contributes as an aid mean in acquiring specific physical qualities and general fitness ${ }^{(\mathbf{1 0})}$.

It is an effective mean to train both static and dynamic balance, and also to train motor skills, motor skills and proprioception; while training on an unstable surface, the core muscles automatically fires and contracts to keep the body upright. Thus, the BOSU challenges individuals to increase strength and balance simultaneously, also it is used to enhance balance, torso or core strength, and proprioception ${ }^{(11)}$. The best thing about the BOSU, besides its versatility, is that it adds fun to regular workouts ${ }^{(\mathbf{1 2})}$.

\section{Balance training on BOSU ball:}

Balance training is an effective intervention to improve static postural sway and dynamic balance. Both sides up (BOSU) ball is a tool that helps in enhancing postural balance, adding an extra intensity to many different types of training; upper and lower body, core and cardio, challenging body balance, improving core strength, stability ${ }^{(6)}$.

\section{Gait training exercises:}

Gait training is a number of exercises that help for better walking. The exercises involve improving mobility of lower extremity joints, improving strength and balance, and mimicking the repetitive nature of legs that occur during walking ${ }^{(13)}$. 


\section{Treatment procedure:}

Group A: They received physical therapy program of gait training between parallel bars for 30 minutes, the training program was the same for each session as follows: The child stood on a firm mattress in a comfortable position with his/her base of support nearly as the shoulder width between parallel bars, the therapist stood behind the child, assist him/her if needed, and encouraged the child to walk in an erect, upright position and to take steps while keeping his/her balance, he/she can hold on the bars if needed, for 30 minutes.

Group B: They received physical therapy program of gait training in addition to physical therapy program to improve balance using BOUS ball with the stand bar for holding on when needed, the training program was the same each session for an hour. All exercises were done on the dome side of the BOSU ball 4 minutes for each exercise, and rest period were given according to each child when needed. The exercises were:

1) Standing on BOSU ball.

2) Standing with closed eyes on BOSU ball.

3) Standing with feet together on BOSU ball.

4) Step standing on BOSU ball.

5) One leg stance on BOSU ball.

6) Turning $360^{\circ}$ while standing on the BOSU ball.

7) Tracking an object behind shoulders while standing on BOSU ball.

8) Pick up an object while standing on BOSU ball.
9) Reaching forward with outstretched arm while standing on BOSU ball.

10) Kneeling on BOSU ball.

11) Squatting on BOSU ball.

12) Balancing reverse lunges on BOSU ball.

13) Four point contra-lateral limb extension on BOSU ball.

14) Airplane on BOSU ball.

15) Walk up on BOSU ball.

\section{Statistical analysis}

Results were expressed as mean $\pm \mathrm{SD}$, number and percentage. Pearson chi-square and unpaired t-test were used to analyze gender and age distribution between groups. To examine the normality of the data Kolmogorov-Smirnov statistic with Lilliefors significance level and Shapiro-Wilk test were used. The quantitative data of this study were normally distributed. So, the comparison between PBS scores of T1, T2 and T3 values among the two groups was done using unpaired t-test. Analysis of variance (repeated measures ANOVA) and post-hoc test were used to compare the three consecutive measures of PBS scores of T1, T2 and T3 values within each group.

\section{RESULTS}

Both gender and age showed a statistically insignificant difference between study group and control group (Table 1).

Table (1): Demographic data in the two groups

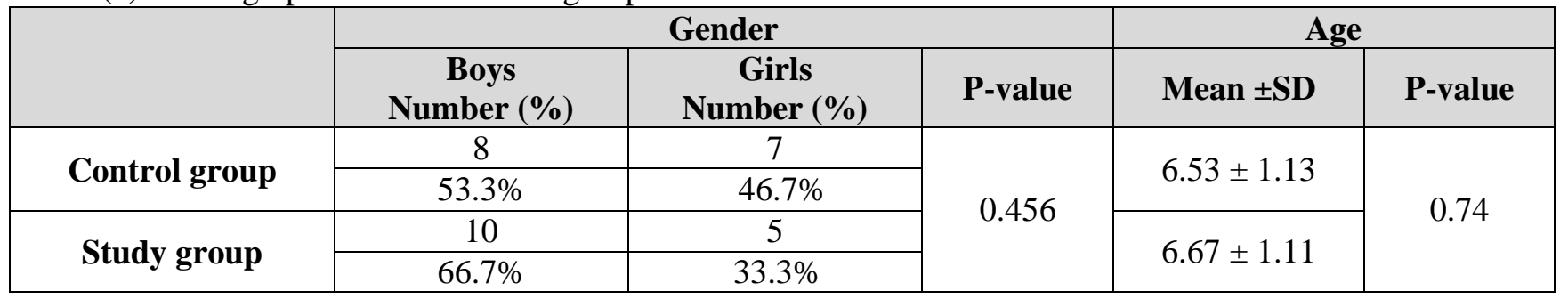

Table 2 illustrated the comparisons within each group between T1, T2 and T3 of PBS score. Both groups showed a statistically significant difference.

Table (2): Comparisons within each group between baseline T1, pre-treatment T2 and post-treatment T3 of PBS score

\begin{tabular}{|c|c|c|c|}
\hline & Time of Evaluation & Mean \pm SD & P-value \\
\hline \multirow{3}{*}{ Control group } & Baseline T1 & $30.93 \pm 2.71$ & \multirow{2}{*}{$<0.001$} \\
\cline { 2 - 3 } & Pre-treatment T2 & $16.13 \pm 2.20$ & \multirow{2}{*}{$<0.001$} \\
\cline { 2 - 3 } Study group & Post- treatment T3 & $25.60 \pm 1.88$ & \multirow{2}{*}{$<0.60 \pm 2.82$} \\
\cline { 2 - 3 } & Baseline T1 & $15.93 \pm 2.02$ & $36.93 \pm 1.94$ \\
\cline { 2 - 3 } & Pre-treatment T2 & Post- treatment T3 & \\
\hline
\end{tabular}

Table 3 showed that there was a statistically insignificant difference between groups for T1, T2 and T3. 
Table (3): Comparisons of PBS score for all times of measurement, baseline T1, pre-treatment T2 and posttreatment $\mathrm{T} 3$, between groups

\begin{tabular}{|c|c|c|c|}
\hline $\begin{array}{c}\text { PBS score } \\
\text { Time of Evaluation }\end{array}$ & Group & Mean $\mathbf{E S D}$ & \multirow{2}{*}{ P-value } \\
\hline \multirow{2}{*}{ Baseline T1 } & Control group & $30.93 \pm 2.71$ & \multirow{2}{*}{0.744} \\
\cline { 2 - 3 } & Study group & $30.60 \pm 2.82$ & \multirow{2}{*}{0.797} \\
\cline { 2 - 3 } Pre-treatment T2 & Control group & $16.13 \pm 2.20$ & \multirow{2}{*}{$<0.001$} \\
\hline \multirow{2}{*}{ Post-treatment T3 } & Study group & $15.93 \pm 2.02$ & $25.60 \pm 1.88$ \\
\cline { 2 - 3 } & Control group & $36.93 \pm 1.94$ & \\
\hline
\end{tabular}

\section{DISCUSSION}

The current study aimed to evaluate the therapeutic effect of static and dynamic balance exercises using both sides up (BOSU) ball on balance in children with acute lymphoblastic leukemia (ALL) 6 months after finishing their chemotherapy treatment. The BOSU ball is a fun and kid-friendly tool for balance training as it added fun to usual workouts and encourages children patients ${ }^{(\mathbf{1 2})}$.

The results of this study support the use of balance training exercises (static and dynamic) for children with acute lymphoblastic leukemia with BOSU ball as it enhance balance, torso or core strength, and proprioception ${ }^{(11)}$.

In the current study there was a significant affection of balance performance measured at T1 before chemotherapy treatment could be attributed to ability of cancer to affect nerves by direct infiltration, pressure by tumor, fibrosis from radiation therapy, neurotoxicity from chemotherapy, or paraneoplastic disorders. Neurologic complications in cancer patients can affect any level of the central and peripheral nervous system. Direct involvement includes brain metastasis, intramedullary spinal cord metastasis, epidural spinal cord compression, leptomeningeal metastases, and cranial or peripheral neuropathies ${ }^{(\mathbf{1 4})}$.

These T1 results of decreased postural balance performance were also revealed by Gilchrist and Tanner ${ }^{(2)}$, who found that $50 \%$ of their participants had balance impairment even before starting the chemotherapy. It is likely due to the effect of the disease or medical treatment that was given during the diagnostic phase.

The significant affection of postural balance performance denoted when comparing between $\mathrm{T} 1$ before chemotherapy treatment and T2 after chemotherapy treatment for six months before physical therapy treatment, indicates that chemotherapy treatment of ALL can affect balance through various mechanisms, including sensory and motor peripheral neuropathy, cognitive impairment, and reduced muscle strength and flexibility ${ }^{(15)}$.

The current study revealed a significant improvement of balance performance in study group more than control group. This could be attributed to using BOSU ball as a training tool for balance which plays an essential role in promoting balance, torso or core strength, and proprioception. Rehabilitation intervention has great possibility to alleviate the effect of cancer and its treatment, and may have a role in reducing morbidity and mortality rates ${ }^{(\mathbf{1 6})}$.

Additionally, the results of the present study comes in agreement with Huang and Ness ${ }^{(17)}$, who reported that focusing of ALL children in engaging in physical activities is noticeable, because ALL pediatric patients can often exhibit some symptoms of depression such as negative mood, interpersonal problems, ineffectiveness, anhedonia, and negative self-esteem. Physical exercise training, as well as enjoyable activities, can enhance a relationship of trust and security between the subjects concerned, improve the child's psychological aspect, enhance the importance of the interpersonal component and improve the overall quality of life of ALL children.

\section{CONCLUSION}

From the obtained results, it can be concluded that balance exercises using both sides up (BOSU) ball can be used effectively in treating balance defect post chemotherapy in children with acute lymphoblastic leukemia as it is a safe, effective in improving both static and dynamic balance, as well as training motor skills, kinesthetic awareness, proprioception and core muscles, and finally it adds fun to children in the psychological aspect.

\section{REFERENCES}

1. Hunger S, Antillon F (2014): Acute lymphoblastic leukemia, In: Stefan DC, Rodriguez-Galindo C (eds), 
Pediatric hematology oncology in countries with limited resources, Springer, New York; Pp. 225-38.

2. Gilchrist L, Tanner L (2018): Short-term recovery of balance control. Pediatr Phys Ther., 30(2):119-124.

3. Galea V, Wright M, Barr R (2004): Measurement of balance in survivors of acute lymphoblastic leukemia in childhood. Gait Posture, 19(1):1-10.

4. Regine S, Katharina $E$ (2015): Impairments of Lower Extremity Muscle Strength and Balance in Childhood Cancer Patients and Survivors: A Systematic Review. Pediatric Hematology and Oncology, 32: 585-612.

5. Carolina S, Giorgio Z, Alberto $M$ et al. (2018): Physical training interventions for children and teenagers affected by acute lymphoblastic leukemia and related treatment impairments. Oncotarget., 9(24): 17199-17209.

6. Zech A, Hubscher M, Vogt L et al. (2010): Balance training for neuromuscular control and performance enhancement, a systematic review. Journal of Athletic Training, 45(4): 392-403.

7. Morawietz C, Moffat F (2013): Effects of locomotor training after incomplete spinal cord injury: A systematic review. Archives of Physical Medicine and Rehabilitation, 94(11): 2297-2308.

8. Franjoine M, Darr N, Sharon L et al. (2010): The performance of children developing typically on the pediatric balance scale. Pediatric Physical Therapy, 22: 350-359.

9. Franjoine M, Gunther J, Taylor M (2003):
Pediatric Balance Scale: A Modified Version of the Berg Balance Scale for the School-Age Child with Mild to moderate motor impairment. Pediatric Physical Therapy, 15(2): 114-28;

10. Badr N (2013): The effects of BOSU ball training on teaching and improving the performance of certain handball basic skills. Science, Movement and Health, 2: 498-505.

11. Cary W (2014): The BOSU Ball. ACSM'S Health \& Fitness Journal, 18(4):5-7.

12. Proske U, Gandevia S (2012): the proprioceptive senses: their roles in signaling body shape, body position and movement, and muscle force. Physiol Rev., 92(4):1651-1697.

13. Brett $\mathbf{S}$ (2020): Gait training exercises in physical therapy. https://www.verywellhealth.com/gaittraining-in-physical-therapy-5069884

14. Newton H (1999): Neurologic complications of systematic treatment. Am F Phys., 59: 878-86.

15. Varedi M, McKenna R, Lamberg E (2017): Balance in children with acute lymphoblastic leukemia. Pediatrics International, 59: 293-302.

16. Tanner L, Keppner K, Lesmeister $D$ et al. (2020): Cancer rehabilitation in the pediatric and adolescent/young adult population. Semin Oncol Nurs., 36(1):150984-88.

17. Huang T, Ness $K$ (2011): Exercise interventions in children with cancer. A review. Int J Pediatr., 461512 16. 